\title{
Burnout and psychological distress among nurses in a Nigerian tertiary health institution
}

\author{
Okwaraji FE ${ }^{1}$ Aguwa EN ${ }^{2}$
}

1. Department of Psychological Medicine, College of Medicine, University of Nigeria Nsukka.

2. Department of Community Medicine, College of Medicine, University of Nigeria Nsukka.

\begin{abstract}
Background: The role of nurses in the health care delivery system cannot be overemphasized. Nurses are needed at all levels of healthcare and the profession requires a lot of dedication, time and energy with regards to patient management and service delivery. This time investment and dedication to duty is likely to lead to burnout and psychological distress among the nurses.
\end{abstract}

Objective: This study assesses the prevalence of burnout and psychological distress among nurses working in Nigerian tertiary health institution.

Method: The Maslach Burnout Inventory (MBI) and the General Health Questionnaire (GHQ-12) were used to assess 210 nurses working in this health institution for symptoms of burnout and psychological distress.

Results: High levels of burnout were identified in $42.9 \%$ of the respondents in the area of emotional exhaustion, $47.6 \%$ in the area of depersonalization and $53.8 \%$ in the area of reduced personal accomplishment, while $44.1 \%$ scored positive in the GHQ-12 indicating presence of psychological distress.

Conclusion: Prevalence of burnout and psychological distress is high among nurses.

Key words: Burnout, psychological distress, stress management.

African Health Sciences 2014;14(1): 237-245 http://dx.doi.org/10.4314/ahs.v14i1.37

\section{Introduction}

The concept of burnout was first introduced by Herbert Freudenberger who described burnout as a condition characterised by such feelings as emotional exhaustion, disillusionment and withdrawal which he initially noticed among voluntary health workers ${ }^{1}$. Burnout is a psychological term for the negative response to chronic job-related stress. It is said to occur when people give too much of their time, energy and effort on their job over a long period of time without enough time to recover physically or emotionally ${ }^{2}$. Ibikunle et al. ${ }^{3}$ defined burnout as a state of physical, emotional and mental exhaustion caused by long term involvement in situations that are emotionally demanding. The development of the Maslach Burnout Inventory (MBI) 4,5 which is the most widely used instrument to measure burnout has long settled the question of how to define burnout. Maslach ${ }^{5}$ defined burnout as having three components as follows: emotional exhaustion which according to him is the feelings of fatigue and of being drained by one's work; Depersonalization which he said is the negative attitude towards and a dehumanizing

\section{Correspondence author:}

Okwaraji FE

Department of Psychological Medicine, College of Medicine, University of Nigeria Nsukka

E-Mail: Friday.okwaraji@unn.edu.ng treatment of one's clients in the work place; and reduced personal accomplishment which has to do with lack of feelings of competence and achievements in one's work with people. According to Embriaco et al. ${ }^{6}$ some of the clinical symptoms of burnout include tiredness, headache, eating problems, insomnia, irritability, emotional instability and rigidity in relationship with other people.

Many researches had been conducted on burnout syndrome among various professional groups including nurses. For instance, Thorsen et al. ${ }^{2}$ in a study of high rates of burnout among maternal health staff in Malawi reported that $72 \%$ of their subjects reported emotional exhaustion, $43 \%$ reported depersonalization while $74 \%$ reported reduced personal accomplishment. They concluded that burnout appeared to be common among maternal health staff that participated in the study when compared with their colleagues working in other medical settings. Embriaco et al. ${ }^{6}$ in their review of Burnout syndrome among critical care healthcare workers observed that Burnout syndrome as measured by the Maslach Burnout inventory is present in about $50 \%$ of critical care physicians and in one third of critical care nurses with severity of burnout being related to the number of working hours of the critical care staff. The higher the working hours the more severe the burnout syndrome experienced. Abdulla et al. ${ }^{7}$ looked at the prevalence and determinants of burnout syndrome 
among primary health care physicians in Qatar and reported that $12.6 \%$ of all the general practitioners who took part in the study experienced burnout. Lasebikan and Oyetunde ${ }^{8}$ in their study on burnout among nurses in a Nigerian general hospital found a high level of burnout in $39.1 \%$ of their respondents in the area of emotional exhaustion, $29.2 \%$ in the area of depersonalization and $40.0 \%$ in the area of reduced personal accomplishment.

They recommended that government needs to look into the factors that will enhance nurses' recruitment and retention for effective healthcare delivery system in Nigeria. In a related study with physiotherapists Ibikunle et al. ${ }^{3}$ reported that $66.2 \%$ of their subjects exhibited emotional exhaustion, $65.2 \%$ showed high levels of depersonalization and $75.6 \%$ showed high levels of reduced personal accomplishments on the Maslach burnout inventory. Variations in the prevalence of burnout syndrome in healthcare professionals have been documented. These include doctors ${ }^{9}$, nurses ${ }^{10}$, oncologists ${ }^{11}$, and physicians caring for patients with AIDS ${ }^{12}$ and community health personnel of primary care units ${ }^{13}$.

The role of nurses in the healthcare delivery system in Nigeria and indeed all over the world is very significant; nurses occupy a central role in health delivery of every country, though many countries may have different health care systems and payment options. Nursing as a profession requires investing a lot of time and energy in relationship with people seeking treatment and care, often in trying circumstances. Burnout is likely to be heightened in these potentially intense and demanding circumstances. Furthermore the nursing environment also has elements that are likely to increase the feelings of burnout including heavy workloads, lack of adequate resources to work with, lack of respect from doctors and little input into unit decision making and psychological distress as well as job dissatisfaction ${ }^{14}$.

Aiken et al. ${ }^{15}$ have reported negative attitudes and low psychological and physical wellbeing among nurses with many of them expressing strong feelings to leave the profession. Burke et al. ${ }^{14}$ argued that there are indications that nursing as a profession is becoming less attractive for young women and men than it was in the past, that some countries even report shortage of nurses and this is even compounded by the fact that richer nations are luring nurses away from poorer ones.
Lasebikan and Oyetunde ${ }^{8}$ have argued that the incidence of occupational stress related burnout among nurses is very high. The factors they pointed out to be associated with burnout among nurses include age of the nurse, number of years on the nursing job, the rank of the nurse in the establishment as well as inadequate staff to patient ratio. They further observed that a growing recognition of job stress leading to dissatisfaction among registered nurses in Nigerian hospitals is a major contributory factor to current problems associated with recruitment and retention of nurses in the country. They therefore suggested that if nurse administrators can identify these factors, nurses' turnover rate will decrease thereby increasing recruitment and retention of nurses in the country. Equally Lambert et al. ${ }^{16}$ had observed high incidences of occupational stress related burnout among nurses in Paris. Jenkins and Elliot ${ }^{17}$ in London noted that factors such as age, years of work and the rank of the nurse in the organization are also associated with the level of burnout and psychological distress experienced by nurses. Other factors like inadequate staff, handling difficult patients, inadequate clinical supervision, excess workload, emotional stress, conflict with staff and lack of adequate social support have also been identified by various researchers to be related to burnout and psychological distress among nurses ${ }^{18,19,20}$.

Though many studies had been conducted on burnout among nur ses in Nigeria, but most of these studies had not critically looked at burnout and psychological distress among this professional group. The present study is therefore an attempt to explore burnout and psychological distress among nurses in a Nigerian tertiary health institution with a view to making recommendations on how to reduce the negative consequences of burnout and psychological distress among nurses and professionals in the health sector and also help to add to the health promotion campaign of the government.

\section{Method}

Study Design: It was a cross sectional descriptive study carried out between February and March 2013.

Study Setting: The study was carried out at the University of Nigeria Teaching Hospital (UNTH) Ituku Ozalla, in Enugu State of Nigeria. Enugu State is a mainland state in South East Nigeria. It has very large deposits of coal, hence it is also known as the coal city state. 
It occupies an area of about 7,161 square kilometres. The state has a population of about $5,590,513$. The University of Nigeria Teaching Hospital is a federal tertiary health institution and a center of excellence in healthcare delivery in south eastern region of Nigeria. It serves virtually all the south eastern states and beyond. The hospital has 500 bed capacity and 21 clinical departments. It covers an area of 200 acres of land.

Study Subjects: Subjects for the study were nurses working at the various clinical departments of the hospital. The total number of nurses in the clinical department was 1573. Study participants were selected from this sample frame through convenience sampling method. The purpose and procedures of the study was fully explained to them. They were also assured that their responses will be treated confidentially and no respondent will be identified in person, and that participation was voluntary. All the respondents agreed to participate and signed the consent form. 10 nurses were sampled from each clinical department making a total of 210 nurses that took part in the study.

Ethical approval for this study was obtained from the University of Nigeria Teaching Hospital Ethical Committee.

Data collection and Instruments: Data was collected by the authors with the help of two psychology interns. The subjects were given a self-administered instrument that was made up of three parts. Part one contains basic demographic information such as age, gender, marital status, education, religion, rank and number of years practiced as a nurse in the hospital.

Part two was the Maslach Burnout Inventory (MBI), which is a 22 item questionnaire that relates to the three dimensions of burnout: Emotional exhaustion (EE, 9 items), which captures the experience of having ones emotional resources depleted and having no source of replenishment. EE subscale items describe feelings of being emotionally overextended and exhausted by one's work (e.g. I feel like I am at the end of the rope). (b) Depersonalisation (DP, 5 items) describes the experience of becoming cold and indifferent to the need of others. DP subscale items capture negative and cynical feelings about one's patients or colleagues (e.g. I don't really care to what happens to some patients) (C) Reduced personal accomplishment (PA, 8 items) is a sense of inadequacy about one's ability to relate to patients which may result in a self imposed verdict of 'failure'. PA subscale items assess how one perceives his or her competence (e.g. I deal very effectively with the problems of my patients). The respondents rated each item on a seven- point likert type scale for how frequently they experienced the feeling $(0=$ never, $6=$ every day). The scale was scored by calculating subscale means ${ }^{5}$. Maslach and Jackson ${ }^{4}$ reported reliability coefficients of 0.90 for EE; 0.79 for $\mathrm{DP}$ and 0.71 for PA with test-retest reliabilities ranging from 0.50 to 0.82 for the three subscales. Both the convergent and discriminant validity of the MBI have been established ${ }^{5}$.

The MBI have been sighted in over 500 studies since it was developed more than 20 years ago and this made it to be regarded as the most viable instrument for the assessment of burnout ${ }^{2}$. Furthermore in Nigeria the MBI has been validated and used in many studies on burnout among different population groups including nurses, doctors, psychologists and teachers ${ }^{3,9,22,23}$. This wide usage of the MBI for various researches in Nigeria therefore justifies its usage in the present study. Part three is the General Health Questionnaire (GHQ12). The GHQ- $12^{24}$ is an instrument used to screen for psychiatric morbidity. Although it does not yield a diagnosis, positive scores are indicative of psychological distress. Each item is rated 0 or 1 on the basis of the frequency with which the subject had experienced the symptom in the recent past, yielding a maximum score of 12. In the GHQ-12 subjects are asked to indicate, for instance, how recently they have been able to concentrate on whatever they have been doing. The response options include; better than usual, same as usual, less than usual and much less than usual. A score of 1 or above is suggestive of psychological distress. The GHQ has been used for studies in Nigeria ${ }^{8}$.

Data Analysis: The data for this study was analysed using SPSS version 15.0. Frequency tables and percentages were used to compare certain demographic variables such as age, gender, marital status, educational level and hierarchy, while Chi square was used to test for significant relationships between variables. Binary logistic regression was done to predict the probability of a nurse developing burnout and psychological distress. The level of significance chosen for this study was $\mathrm{p} \leq 0.05$ and Confidence Interval was 95\%.

Study limitation: The most important limitation of this study is that recent events may have a disproportionate influence on respondents' mood at the time the test was taken. 
Study Strength: The data collecting tools [Maslach Burnout Inventory and General Health Questionnaire (GHQ-12)] are validated and have been extensively used in previous studies.

\section{Results}

A total of 210 nurses participated in the study and properly completed the survey instruments given a proper response rate of $100 \%$. Table 1 shows the demographic characteristics of the respondents.

Table 1 - Socio-demographic characteristics of the respondents

\begin{tabular}{|c|c|c|}
\hline \multirow{2}{*}{\multicolumn{3}{|c|}{ Frequency $(\mathrm{N}=210)$}} \\
\hline & & \\
\hline$\leq 35$ & 117 & 55.7 \\
\hline$>35$ & 93 & 44.3 \\
\hline \multicolumn{3}{|l|}{ Gender } \\
\hline Male & 40 & 19.0 \\
\hline Female & 170 & 81.0 \\
\hline \multicolumn{3}{|l|}{ Marital Status } \\
\hline Single & 59 & 28.1 \\
\hline Married & 151 & 71.9 \\
\hline \multicolumn{3}{|l|}{ Educational Level } \\
\hline Nursing certificate & 181 & 86.2 \\
\hline Nursing degree & 29 & 13.8 \\
\hline \multicolumn{3}{|l|}{ Religion } \\
\hline Christianity & 197 & 93.8 \\
\hline Others & 13 & 6.2 \\
\hline \multicolumn{3}{|l|}{ Years of Service } \\
\hline$\leq 5$ & 13 & 6.2 \\
\hline$>5$ & 197 & 93.8 \\
\hline \multicolumn{3}{|l|}{ Rank } \\
\hline Nursing Officer & 71 & 33.8 \\
\hline $\begin{array}{l}\text { Senior nursing officer } \\
\text { and above }\end{array}$ & 139 & 66.2 \\
\hline
\end{tabular}

Age range $=25-50$ years; mean $=35.5 ; \mathrm{SD}=8.34$

Years of service: range $=5-23$ years; mean $=5.6 ; \mathrm{SD}=2.60$

They were 210 in all. $81.0 \%$ were females, $71.0 \%$ were married. The age range of the respondents was 25 to 50 years. The mean age was $35.5 \pm 8.34$ years. $57.7 \%$ were less than 35 years of age. $86.2 \%$ had nursing certificates and majority of the nurses were Christians (93.8\%). Furthermore $93.8 \%$ had worked for more than 5 years. In terms of rank $66.2 \%$ were the ranks of senior nursing officer and above. $44.1 \%$ scored positive in the GHQ indicating presence of psychological distress.

Prevalence of Burnout: A high level of burnout was identified in $42.9 \%$ of the respondents in the area of emotional exhaustion (EE), $47.6 \%$ in the area of depersonalization (DP) and $53.8 \%$ in the area of reduced personal accomplishment (RPA). This was significant, $\chi^{2}=7.1, \mathrm{df}=(1), \mathrm{p}=0.01$ (Table 2) 
Table 2 - Prevalence of Burnout

\begin{tabular}{|c|c|c|c|c|c|}
\hline \multicolumn{5}{|c|}{ Burnout measurements } \\
\hline \multicolumn{2}{|c|}{ Emotional Exhaustion } & \multicolumn{2}{|c|}{ Depersonalization } & \multicolumn{2}{|c|}{$\begin{array}{c}\text { Reduced Personal } \\
\text { Accomplishment }\end{array}$} \\
\hline Yes & No & Yes & No & Yes & No \\
$(\%)$ & $(\%)$ & $(\%)$ & $(\%)$ & $(\%)$ & $(\%)$ \\
\hline 90 & 120 & 100 & 110 & 113 & 97 \\
$(42.9)$ & $(57.1)$ & $(47.6)$ & $(52.4)$ & $(53.8)$ & $(46.2)$ \\
\hline
\end{tabular}

Variables Predicting Burnout: All the demographic nurses aged less than 35 years, females, those not variables measured that is age, gender, marital status, married and those with nursing certificates as compared educational level, and years of service and rank were to those with nursing degrees and those working as found to significantly affect burnout measurements, nursing officers, (Table 3). $(\mathrm{p}<0.01)$, see Table 3. Burnout occurred more in the

Table 3 - Socio-demographic variables and burnout measurements

\begin{tabular}{|c|c|c|c|c|c|c|}
\hline \multirow[t]{2}{*}{ Variable } & \multicolumn{2}{|c|}{$\begin{array}{l}\text { Emotional Exhaus- } \\
\text { tion (Yes) } \\
\mathrm{N}=90\end{array}$} & \multicolumn{2}{|c|}{$\begin{array}{l}\text { Depersonalization } \\
\text { (Yes) } N=100\end{array}$} & \multicolumn{2}{|c|}{$\begin{array}{l}\text { Reduced Personal } \\
\text { Accomplishment (Yes) } \\
\mathrm{N}=113\end{array}$} \\
\hline & $\begin{array}{l}\text { Frequency } \\
(\%)\end{array}$ & $\begin{array}{l}\chi^{2} \quad(\mathrm{P} \\
\text { Value) }\end{array}$ & $\begin{array}{l}\text { Frequency } \\
(\%)\end{array}$ & Value & $\begin{array}{l}\text { Frequency } \\
(\%)\end{array}$ & P Value \\
\hline $\begin{array}{r}\text { Age (years) } \\
\leq 35 \\
>35\end{array}$ & $\begin{array}{l}90(100.0) \\
0(0.0)\end{array}$ & $\begin{array}{l}125.19 \\
(<0.01)\end{array}$ & $\begin{array}{l}100(100.0) \\
0(0.0)\end{array}$ & $<0.01$ & $\begin{array}{l}113(100.0) \\
0(0.0)\end{array}$ & $<0.01$ \\
\hline $\begin{array}{l}\text { Gender } \\
\qquad \begin{array}{l}\text { Male } \\
\text { Female }\end{array}\end{array}$ & $\begin{array}{l}40(44.4) \\
50(55.6)\end{array}$ & $\begin{array}{l}65.88 \\
(<0.01)\end{array}$ & $\begin{array}{l}40(40.0) \\
60(60.0)\end{array}$ & $<0.01$ & $\begin{array}{l}40(35.4) \\
73(64.6)\end{array}$ & $<0.01$ \\
\hline $\begin{array}{l}\text { Marital Status } \\
\text { Single } \\
\text { Married }\end{array}$ & $\begin{array}{l}59(65.6) \\
31(34.4)\end{array}$ & $\begin{array}{l}109.40 \\
(<0.01)\end{array}$ & $\begin{array}{l}59(59.0) \\
41(41.0)\end{array}$ & $<0.01$ & $\begin{array}{l}59(52.2) \\
54(47.8)\end{array}$ & $<0.01$ \\
\hline $\begin{array}{c}\text { Educational Level } \\
\text { Nursing } \\
\text { certificate } \\
\text { Nursing degree }\end{array}$ & $\begin{array}{l}61(67.8) \\
29(32.2)\end{array}$ & $\begin{array}{l}44.86 \\
(<0.01)\end{array}$ & $\begin{array}{l}71(71.0) \\
29(29.0)\end{array}$ & $<0.01$ & $\begin{array}{l}84(74.3) \\
29(25.7)\end{array}$ & $<0.01$ \\
\hline $\begin{array}{l}\text { Religion } \\
\text { Christianity } \\
\text { Others }\end{array}$ & $\begin{array}{l}77(85.6) \\
13(14.4)\end{array}$ & $\begin{array}{l}18.48 \\
(<0.01)\end{array}$ & $\begin{array}{l}87(87.0) \\
13(13.0)\end{array}$ & $<0.01$ & $\begin{array}{l}100(88.5) \\
13(11.5)\end{array}$ & $<0.01$ \\
\hline $\begin{array}{c}\text { Years of Service } \\
\leq 5 \\
>5\end{array}$ & $\begin{array}{l}13(14.4) \\
77(85.6)\end{array}$ & $\begin{array}{l}162.11 \\
(<0.01)\end{array}$ & $\begin{array}{l}13(13.0) \\
87(87.0)\end{array}$ & $<0.01$ & $\begin{array}{l}13(11.5) \\
100(88.5)\end{array}$ & $<0.01$ \\
\hline $\begin{array}{ll}\text { Rank } & \\
& \text { Nursing } \\
& \text { Officer } \\
& \text { Senior nursing } \\
& \text { officer and } \\
& \text { above }\end{array}$ & $\begin{array}{l}19(21.1) \\
71(78.9)\end{array}$ & $\begin{array}{l}143.02 \\
(<0.01)\end{array}$ & $\begin{array}{l}29(29.0) \\
71(71.0)\end{array}$ & $<0.01$ & $\begin{array}{l}42(37.2) \\
71(68.8)\end{array}$ & $<0.01$ \\
\hline
\end{tabular}


Similar observations were also noticed in psychological distress evaluation, (Table 4).

Table 4 - Socio-demographic variables and psychological distress

\begin{tabular}{|c|c|c|c|}
\hline \multirow[t]{2}{*}{ Variable } & \multicolumn{2}{|c|}{$\begin{array}{l}\text { Psychological Distress measured using } \\
\text { GHQ-12 }\end{array}$} & \multirow[b]{2}{*}{ PValue } \\
\hline & $\begin{array}{c}\text { Positive } \\
\mathrm{N}=87(\%)\end{array}$ & $\begin{array}{l}\text { Negative } \\
\mathrm{N}=123\end{array}$ & \\
\hline $\begin{array}{l}\text { Age (years) } \\
\quad \leq 35 \\
\quad>35\end{array}$ & $\begin{array}{c}87(100.0) \\
0(0.0)\end{array}$ & $\begin{array}{l}30 \\
93\end{array}$ & $<0.01^{*}$ \\
\hline $\begin{array}{l}\text { Gender } \\
\text { Male } \\
\text { Female }\end{array}$ & $\begin{array}{l}40 \\
47\end{array}$ & $\begin{array}{c}0(0.0) \\
123(100.0)\end{array}$ & $<0.01^{*}$ \\
\hline $\begin{array}{l}\text { Marital Status } \\
\text { Single } \\
\text { Married }\end{array}$ & $\begin{array}{l}59 \\
28\end{array}$ & $\begin{array}{c}0(0.0) \\
123(100.0)\end{array}$ & $<0.01^{*}$ \\
\hline $\begin{array}{c}\text { Educational Level } \\
\text { Nursing certificate } \\
\text { Nursing degree }\end{array}$ & $\begin{array}{l}58 \\
29\end{array}$ & $\begin{array}{c}123(100.0) \\
0(0.0)\end{array}$ & $<0.01^{*}$ \\
\hline $\begin{array}{l}\text { Religion } \\
\text { Christianity } \\
\text { Others }\end{array}$ & $\begin{array}{l}74(85.1) \\
13(14.9)\end{array}$ & $\begin{array}{c}123 \text { 100.0) } \\
0(0.0)\end{array}$ & $<0.01^{*}$ \\
\hline $\begin{array}{l}\text { Years of Service } \\
\quad \leq 5 \\
\quad>5\end{array}$ & $\begin{array}{l}13 \\
74\end{array}$ & $\begin{array}{c}0(0.0) \\
123(100.0)\end{array}$ & $<0.01^{*}$ \\
\hline $\begin{array}{l}\text { Rank } \\
\text { Nursing Officer } \\
\text { Senior nursing } \\
\text { officer and above }\end{array}$ & $\begin{array}{l}16 \\
71\end{array}$ & $\begin{array}{c}0 \\
123\end{array}$ & $<0.01^{*}$ \\
\hline
\end{tabular}

*Significant

Binary logistic regression was then done to predict psychological distress when the demographic variables the probability of a nurse developing burnout and are known (Table 5).

Table 5 - Binary Logistic Regression analysis of variables contributing to Burnout and Psychological distress

\begin{tabular}{|c|c|c|c|c|}
\hline \multirow[t]{3}{*}{ Variables } & \multicolumn{4}{|c|}{ Coefficient of Regression (B) } \\
\hline & \multicolumn{3}{|c|}{ Burnout measurements } & \multirow{2}{*}{$\begin{array}{c}\text { Psychological } \\
\text { Distress }\end{array}$} \\
\hline & $\begin{array}{l}\text { Emotional } \\
\text { Exhaustion }\end{array}$ & Depersonalization & $\begin{array}{l}\text { Reduce Personal } \\
\text { Accomplishment }\end{array}$ & \\
\hline $\begin{array}{l}\text { Age of } \\
\text { respondent }\end{array}$ & 3.310 & 3.546 & 6.034 & 3.137 \\
\hline gender & -16.082 & -18.395 & -15.084 & -16.943 \\
\hline Marital status & -7.785 & -8.647 & -45.644 & -7.311 \\
\hline $\begin{array}{l}\text { Educational } \\
\text { level }\end{array}$ & 19.799 & 22.196 & 18.934 & 20.673 \\
\hline religion & 20.689 & 23.537 & 24.984 & 21.229 \\
\hline Year of service & 16.998 & 19.391 & 15.985 & 17.882 \\
\hline rank & .726 & -20.430 & -15.510 & .735 \\
\hline Constant & -178.796 & -173.235 & -199.631 & -177.791 \\
\hline
\end{tabular}




\section{Discussion:}

The health status of health workers is of great importance if healthcare delivery is to be achieved. As part of occupational health the work environment should be such that it does not endanger the health of those who work. Incidentally work stress has been observed to impact greatly on the health of workers especially in some professions like teaching, nursing and other health workers like doctors and psychologists. This study has revealed that burnout was highly prevalent among the nurses who took part in the study. It also showed that the nurses have high prevalence of psychological distress. The authors noticed significant difference in the prevalence of burnout across the three dimensions of emotional exhaustion, depersonalization and reduced personal accomplishment. Furthermore all the demographic variables measured were found to significantly affect burnout levels. Similar observations were also noticed in the area of psychological distress evaluation.

Female nurses recorded high levels of burnout than males in the area of emotional exhaustion, depersonalization and reduced personal accomplishment. This finding was in line with an earlier report by Kalimo et al ${ }^{25}$ who reported that both sexes differ significantly in the ways they cope with stress. This higher levels of burnout experienced by females may be attributed to the present economic situation in the country where most women especially the married ones play a dual role of homemaker where they do full household work including child caring and also work full time in their various offices and professions as career ladies. This dual role may likely predispose them to experiencing many job related stress which eventually will affect their burnout than their male counterparts who may usually after coming back from work may decide to visit a nearby drinking house to ease off the day's tension.

Our study also revealed that nurses aged less than 35 years of age experienced significantly higher levels of burnout in the three dimensions than the elderly nurses aged more than 35 years of age. This pattern of finding was equally reported by Edwards et al ${ }^{18}$. This may be because the younger nurses might not have acquainted themselves with the vagaries of the nursing profession and might not have developed enough psychological resilience to cope with the many challenges associated with their job, unlike the older nurses.

We equally noticed high burnout levels among unmarried nurses than those who are married. Unmarried nurses may experience higher levels of burnout than the married ones apparently due to the fact that they are younger and may be assigned more work than their elderly and senior counterparts. Moreover married female nurses usually take maternity leave which will give them opportunity to rest in their homes and recover from the stress associated with the working environment. Furthermore Adekola ${ }^{22}$ had argued that family life tends to strengthen one's emotional wellbeing, human contacts and interpersonal skills. He further argued that married women whose husbands help in housework and family responsibilities and support their carrier development are less prone to burnout than women who do not have such assistance. This may explain why unmarried women have higher levels of burnout than the married ones in this study.

Those in the rank of senior nursing officer and above experienced higher burnout levels than those in the rank of nursing officer. This may be attributed to the practice whereby senior nursing officers are constantly under pressure to ensure patient's satisfaction as they usually play supervisory roles over the junior officers to ensure compliance to the globally accepted standards in the nursing profession with regards to care. This may make them to overlabour themselves and then be predisposed to higher stress with the associated burnout and psychological distress.

The high prevalence of burnout and psychological distress noticed among our subjects of study had clearly demonstrated that burnout is a negative response to chronic job related stress, which arises when people give too much of their time, energy and effort on their job over a long time without having much time to recover physically or emotionally ${ }^{2,3}$. This study in general also corroborates that of Aiken et al ${ }^{15}$ who reported negative attitudes and low psychological wellbeing among nurses. The high levels of burnout and psychological distress observed among these nurses invariably can affect their job satisfaction, organizational commitment and intention to quit ${ }^{26}$, as well as their work to family and family to work conflict ${ }^{27}$. This may also manifest in both physical and behavioural symptoms of stress such as depression, anxiety, irritability, headache and insomnia as had been reported by many authors in Nigeria and other parts of the world ${ }^{7,9,28,29,30}$.

\section{Conclusion}

This study has revealed high prevalence of burnout and 
psychological distress among the nurses in a Nigerian tertiary health institution. Some demographic variables like sex, age, cadre, educational status, religion and marital status have been shown to significantly affect the likelihood of burnout.

\section{Recommendations}

There is therefore the need for government to liaise with the relevant health professionals to institute regular stress management and stress inoculation programmes for nurses and other health personnel in the country so as to mitigate the negative health consequences associated with burnout and psychological distress. Policy formulations should also recognise the peculiar challenges females and newly employed nurses encounter in their workplaces and put modalities to mitigate presence of workplace stressors.

\section{References}

1. Freudenberger HJ. Staff Burnout. Journal of Social Issues. 1974; 4: 4-20.

2. Thorsen VC, Tharp ALT and Meguid T. High rates of burnout among maternal health staff at a referral hospital in Malawi: A cross sectional study. BMC Nursing. 2011; 10: 9.

3.Ibikunle P, Umeadi $\mathrm{O}$ and Akosile C. The prevalence and pattern of Burnout Syndrome among Nigerian Physiotherapists, The Internet Journal of Chiropractic 2012, 1 (2). Doi: 10.5580/2a65.

4. Maslach C, Jackson, SE and Leiter MP. Maslach Burnout Inventory Manual ( $3^{\text {rd }}$ ed.). Palo Alto, CA: Consulting Psychologists Press. 1996.

5. Maslach C and Jackson SE. The measurement of experienced burnout. Journal of occupational behavior. 1981; 29:99-113.

6. Embriaco N, Papzian L, Kentish-Bames N, Pochard $\mathrm{F}$ and Azoulay E. Burnout syndrome among critical care health care workers. Current Opinions in Critical care 2007;13:482-488.

7. Abdulla L, AL-Qahtani DM and AL-Kuwari MG. Prevalence and determinants of burnout syndrome among primary health care physicians in Qatar. South African Family Practice 2011; 53 (4): 380-383.

8. Lasebikan VO and Oyetunde MO. Burnout among nurses in a Nigerian general hospital: prevalence and associated factors. International Scholarly Research Network, IRSN Nursing 2012, Doi: 10: 5402/2012/402157.

9. Ramirez AJ; Graham J and Richards MA. Mental health of hospital consultants: the effects of stress and satisfaction at work. Lancet 1996, 347: 724-728.

10. LU H, While AE and Barriball KL. Job satisfaction among nurses: A literature Review, International Journal of Nursing Studies 2005. 42:211-227.

11. Lyckholm L. Dealing with stress, burnout and grief in the practice of oncology, Lancet 2001; 2: 750-755.

12. Lert F, Chastang JF, Castano I. Psychological stress among hospital doctors caring for HIV patients in the late nineties. AIDS care, 2001; 13: 763-778.

13. Noosorn $\mathrm{N}$ and Wongwat R. Predictors of burnout among community health personnel of primary care units in the Northern Region of Thailand. Journal of Neuroscience and Behavioral health 2010; 2 (2): 018122.

14. Burk RJ, Greenglass ER. Hospital restructuring, work- family conflict and psychological burnout among nursing staff. Psychological Health 2001; 58: 95-114.

15. Aiken LH, Clark SP, Sloan DM. Hospital Nurse staffing and Patient Mortality, nurse burnout and job satisfaction. JAMA 2002; 288: 1987-1993.

16. Lambert VA, Lambert CE and Ito M. Workplace stressors, ways of coping and demographic characteristics as predictors of physical and mental health of Japanese hospital nurses. International Journal of nursing studies. 2004; 41 (1): 85-97.

17. Jenkins R and Elliot P. Stressors, burnout and social support: nurses in acute mental health settings. Journal of Advanced Nursing 2004; 48 (6): 622-631.

18. Edwards DJ, Burnard P, Hannigan B, Cooper L, Adams J, Juggessur T, et al. Clinical supervision and Burnout: the influence of clinical supervision for community mental health Nurses. Journal of Clinical Nursing. 2006; 15 (8): 1007-1015.

19. Vimantaite R and Seskevicious A. The Burnout syndrome among nurses working in Luthuanian cardiac surgery centers. Medicine 2006; 42 (7): 600-605.

20. Storder S, Dhoore W and Vandenbergh E. Leadership, Organizational stress and emotional exhaustion among hospital nursing staff. Journal of Advanced Nursing. 2001; 35 (4): 533-542.

21. Koeske GF and Koeske RD. Construct validity of the Maslach Burnout Inventory: A Critical Review and Reconceptualization. Journal of Applied Behavioral Science, 1989. 25: 131-144.

22. Adekola B. Gender differences in the experience of work burnout among university staff. African Journal of business management. 2009; 4 (6): 886-889.

23. Ubangha A. Understanding illness behavior, death and bereavement in adulthood. The Counsellor 1997; 
16 (1): 97-103.

24. Goldberg D and the institute of psychiatry. The General health questionnaire-12. Published by GL assessment 1981 (first published 1978). The Chiswick center 414 Chiswick Road, London. http://www.mapitrust.org/questionnaires/8. Accessed on 21st of July 2013.

25. Kalimo AS, Toppinen T, Huuhtanen P, Koskine, A and Vaananen A. Occupational burnout and chronic work disability: An eight year cohort study on pensioning among Finnish forest industry workers. Journal of Affective disorders, 1997; 115(1): 150-159.

26. Campbell DJ and Campbell KM. Global versus Facet predictors of intention to quit: Differences in a sample of male and female Singaporean managers and non managers. International Journal of human resource management. 2003; 14 (7), 1152-1177.

27. Mesmer-Magnus JR and Viswesvaran C. Convergence between measures of work to family and family to work conflict: A meta- analytic examination. Journal of vocational behaviour. 2005; 67: 215-232.

28. Gao YQ, Pan BC and Sun W. Depressive symptoms among Chinese nurses: prevalence and associated factors. Journal of Advanced Nursing. 2011; 3(4): 468474.

29. Bayram N, Gursakal S and Bilgel N. Burnout, Vigour and Job Satisfaction among Academic Staff. European Journal of Social Science 2010; 17 (1): 41-53.

30. Siu O, Spector PE, Cooper CL and Lu C. Work stress, Self efficacy, Chinese work values and work well being in Hong Kong and Beijing. International Journal of stress management. 2005; 12 (3): 274-288. 